\title{
ICongressolnternacionaldas
}

\section{RESÍDUOS DA ATIVIDADE AGROPECUÁRIA: ALTERNATIVA PARA CONVIVÊNCIA COM O SEMIÁRIDO}

\author{
Apresentação: Comunicação Oral
}

\author{
Marileide de Souza Sá ${ }^{1}$; Kellen Cristina Feitosa Barbosa Rosa ${ }^{2}$; Pedro de Assis de Oliveira ${ }^{3}$; \\ Anastácia Brandão de Mélo ${ }^{4}$
}

\begin{abstract}
Resumo
As atividades agropecuárias têm sido objetivo de discussões considerando os impactos ambientais que causam ao meio ambiente, principalmente os resíduos gerados da produção vegetal e animal. A utilização de tecnologias que permitam o reaproveitamento dos resíduos como insumos que possam retornar a natureza, contribuindo para a sustentabilidade do sistema de produção, aliando a consciência da sociedade é de grande importância para o bom desenvolvimento desta prática, já que não utilizam produtos químicos em suas produções, o que ajuda para uma diminuição de uma série de problemas de saúde pública. Para diminuir a ação poluidora surgem tecnologias alternativas que contribuem para o destino dos resíduos como alternativas sustentáveis de geração de energia, composto orgânico e biofertilizantes. A partir desse contexto, o artigo tem como objetivo apresentar as tecnologias adotadas pela agricultura familiar no destino dos resíduos das atividades agropecuárias. A metodologia adotada foi à observação participante e a construção do desenho da propriedade com as famílias, aliado a pesquisa bibliográfica comparativa entre a teoria e realidade e obtendo informações sobre as atividades desenvolvidas na propriedade e seus fluxos, principalmente dos resíduos. De acordo, com as informações coletadas foi possível identificar que o grupo familiar utilizam as tecnologias do biodigestor, compostagem com minhocas e biofertilizante para destinar os resíduos provenientes da produção agrícola e animal, diminuindo os impactos ambientais. A adoção das tecnologias citadas tem grande importância para melhoria da qualidade de vida dos agricultores familiares, diminuindo custos com a produção, geração de renda extra, insumos para a propriedade e integração dos resíduos ao agroecossistema.
\end{abstract}

Palavras-Chave: Agricultura Familiar, Agroecologia, Gestão Ambiental, Tecnologias Sociais.

\section{Introdução}

A agricultura familiar é responsável por garantir alimentos de qualidade oriundos de suas terras, com a participação principalmente dos membros da família, sendo um sistema reconhecido por gerar meios de trabalho em números bem maiores que a agricultura empresarial e por se preocupar com a sustentabilidade socioeconômica e ambiental (BERTÉ, 2014).

\footnotetext{
${ }^{1}$ Graduanda do Curso de Bacharelado em Zootecnia, Universidade Federal Rural de Pernambuco-Unidade Acadêmica de Serra Talhada, e-mail: marileidezootecnista@hotmail.com

${ }^{2}$ Zootecnista, e-mail:kellenfeitosa@gmail.com

${ }^{3}$ Zootecnista, Mestrando em Ciência Animal e Pastagens, Universidade Federal Rural de Pernambuco- Unidade Acadêmica de Garanhuns, e-mail:pedromanari@hotmail.com

${ }^{4}$ Docente do Curso de Bacharelado em Zootecnia, Universidade Federal Rural de Pernambuco-Unidade Acadêmica de Serra Talhada, e-mail: brandaoanastacia@gmail.com
} 
Por isso, vem tendo destaque na produção de alimentos orgânicos em uma forma mais sustentável, sem utilização de agrotóxico e visando o melhor aproveitamento das relações entre o meio ambiente e o homem. Algumas alternativas são utilizadas por famílias de agricultoras para a convivência com o semiárido como um tipo de solução para aproveitamento dos dejetos oriundos da produção agropecuária, onde foram criados meios de tecnologias de baixo custo, como: o biodigestor, biofertilizante e compostagem orgânica a partir desses resíduos.

A consciência da sociedade é de grande importância para o bom desenvolvimento desta prática, já que não utilizam produtos químicos em suas produções, o que ajuda para uma diminuição de uma série de problemas de saúde pública. Com a preservação da biodiversidade e aproveitamento dos resíduos oriundos da propriedade.

Nesse contexto, o artigo tem como objetivo apresentar as tecnologias utilizadas pela agricultura familiar a partir dos resíduos da atividade agropecuária no Assentamento Laginha, localizado no Município de Serra Talhada-PE, analisando os aspectos que auxiliam as práticas de gestão ambiental na propriedade rural.

\section{Fundamentação Teórica}

\section{GESTÃO AMBIENTAL NO DESTINO DE RESIDUOS AGROSSILVOPASTORIS}

O meio ambiente é um bem comum a toda sociedade, com isso, de responsabilidade de todos no que diz respeito a sua utilização e recuperação, sem agredi-lo de forma que futuras gerações possam se beneficiar do seu potencial. Sabemos que de alguma forma o ambiente será afetado nas ações do homem, porém devemos ter consciência de forma sustentável de como se beneficiar deste bem.

Coimbra (1992) nos diz que o mau uso de recursos da natureza, como recursos hídricos, solo, devastações de matas ciliares, tem nos levado a ocorrência de grandes catástrofes ambientais, onde ocorrem mudanças climáticas, perda da biodiversidade, gerando impactos principalmente na agricultura como desmatamentos, poluição das águas e atmosfera, erosão, esgotamento de águas doce, destruição de mananciais e geração de resíduos.

A partir do conhecimento da geração de todos esses problemas, que se geraram discussões acerca desta temática e assim em meados de 1972, vários países se reuniram afim, de decidirem o que fazer para amenizar esses impactos, com isso, ocorreu diversas reuniões onde no Brasil a última Conferência ocorreu no Rio de Janeiro em 2012, conhecida como Rio +20, onde os países reafirmaram o seu compromisso com a sustentabilidade. O Brasil como um dos maiores produtores de produtos agrícolas e consequentemente gerador de impactos citados anteriormente, deve se 
preocupar com trabalhos de gestão da atividade agropecuária (GLOAGEN et al., 2007).

\subsection{Gestão Ambiental e Resíduos Gerados em Atividades Agropecuárias}

A gestão ambiental torna-se importante na atividade agropecuária, pois planeja e organiza a utilização dos recursos naturais de forma sustentável, garantindo assim sua integridade e preservando a biodiversidade. Ou seja, a gestão ambiental auxilia em todo o processo produtivo, evitando problemáticas ambientais e minimizando os impactos negativos, originados pelo empreendimento rural (YURI, 2014).

O processo de gestão ambiental surgiu como uma alternativa para buscar a sustentabilidade dos ecossistemas antrópicos, harmonizando suas interações com os ecossistemas naturais (SEIFFERT, 2014, p. 45). Essa alternativa surgiu a partir dos problemas ambientais que estavam ocorrendo, com uma grande complexidade, precisando assim serem controlados e garantindo a adequação dos usos dos recursos naturais.

Um dos problemas são os resíduos gerados na agropecuária, como o caso da agricultura que um dos principais problemas é o "descarte de seus efluentes, ricos em nutrientes, matéria orgânica e sedimentos. Para viveiros de água doce a troca de águas entre os viveiros e sistemas de irrigação pode ser uma boa solução, uma vez que estes efluentes podem promover algum benefício para determinadas culturas através do aumento da umidade do solo e do fornecimento de pequenas quantidades de nutrientes e matéria orgânica" (ALMEIDA, 2012, p. 131). Assim, o que é um problema pode se tornar uma solução desde que faça gestão ambiental.

Na Lei $n^{\circ} 12.205$ de 2 de agosto de 2011, que institui a Política Nacional de Resíduos Sólidos, os resíduos agrossilvopastoris são os resíduos gerados nas atividades agropecuárias e silviculturais. Assim, os restos de colheita e esterco animal são resíduos gerados durante o processo de produção vegetal e animal.

Dependendo do volume produzido pode provocar impactos poluidores, principalmente se não houver uma destinação adequada dos desejos animais. De acordo com a EMBRAPA (2015), os resíduos animais possuem uma capacidade poluidora, por isso as propriedades rurais devem adotar uma gestão ambiental adequada para resolver esse problema, buscando tecnologias para o tratamento dos resíduos.

Nesse contexto, torna-se importante utilizar tecnologias que permitam o reaproveitamento dos resíduos como insumos que possam retornar a natureza, contribuindo para a sustentabilidade do sistema de produção. 


\subsection{Convivência com o semiárido}

O semiárido brasileiro é caracterizado por chuvas (precipitações) irregulares, índices de temperaturas elevadas e tem como bioma principal a Caatinga que é o único bioma exclusivamente brasileiro e rico em espécies nativas de vegetais que bem manejado são de grande potencialidade para o uso na alimentação animal.

A convivência com o semiárido, trata-se da utilização de técnicas ambientais que possam diminuir as consequências causadas pelo momento de escassez de chuvas, que tem impactos direto na produção de alimentos, que é utilizado principalmente para o consumo humano e animal. "Segundo a abordagem agroecológica, é essencial que entenda a dinâmica de funcionamento da natureza para que as atividades econômicas sejam harmonizadas aos ciclos naturais. Em outras palavras, conviver significa tirar partido dos potenciais naturais que, no semiárido, são imensos e ainda pouco conhecidos e valorizados" (PETERSEN, 2013, p. 60).

Várias tecnologias são utilizadas para conviver com o semiárido, dentre elas, conservação de alimentos na forma de silagem e feno, armazenamento de água em cisternas, entre outros. Porém, é importante observar que cada lugar tem suas características próprias. Por essa razão, algumas implementações podem ser desenvolvidas em alguns locais, mas não em outros. Ou seja, cada tecnologia, inovação ou experiência precisa das condições ideais para sua implantação (ASA, 2010).

A importância de ter tecnologias dentro das propriedades rurais para a utilização e aproveitamento dos resíduos gerados, contribui de forma positiva para a sustentabilidade ambiental e manejo adequado para o solo, podendo devolver a ele os nutrientes necessários para uma boa nutrição. O biogás, compostos orgânicos, biofertilizantes e outros, são algumas técnicas que visam o retorno desses nutrientes e contribui de forma social e econômica para a atividade agropecuária.

\section{Metodologia}

O presente artigo é resultado de uma visita técnica da disciplina de Gestão Ambiental do Curso de Bacharelado em Zootecnia da Universidade Federal Rural de Pernambuco, Unidade Acadêmica de Serra Talhada. Tendo o objetivo conhecer práticas de gestão ambiental na agricultura familiar num assentamento de reforma agrária.

A partir da observação participante e da construção do desenho da propriedade com a família foi possível obter informações sobre as atividades desenvolvidas na propriedade e seus fluxos, principalmente dos resíduos. De acordo com Cruz Neto (2001, p. 59, grifo do autor) “a 
técnica de observação participante se realiza através do contato direto do pesquisador com o fenômeno observado para obter informações sobre a realidade dos atores sociais em seus próprios contextos".

Para Drumond (2009), o desenho de mapas objetiva visualizar os aspectos ambientais e sociais da área, além de facilitar a identificação dos locais e recursos disponíveis na propriedade.

Para o desenvolvimento do artigo buscou na pesquisa bibliográfica a teoria a respeito do tema para articular com a realidade observada, bem como, ilustrações das tecnologias no assentamento com fotos.

\section{Resultados e Discussão}

A propriedade denominada Lote 03, do assentamento Laginha (Figura 1), está localizada a $18 \mathrm{Km}$ da sede, em direção ao distrito de Santa Rita, no município de Serra Talhada-PE, conforme figura 2, na Mesorregião do Sertão Pernambucano, Microrregião do Pajeú, a uma altitude de 429 metros. O lote 03 do Assentamento Laginha, dispõe de uma Residência familiar, Cisterna de enxurrada de 16.000 litros, criatório de caprinos, ovinos, bovinos, suínos e galinha caipira, minhocário, biodigestor, biofertilizante, Poço amazonas, área com plantações de hortaliças, fruteiras, capins e demais culturas de alimentação humana e animal.

Figura 1 - Identificação da propriedade na chegada ao Assentamento. Fonte: Própria.

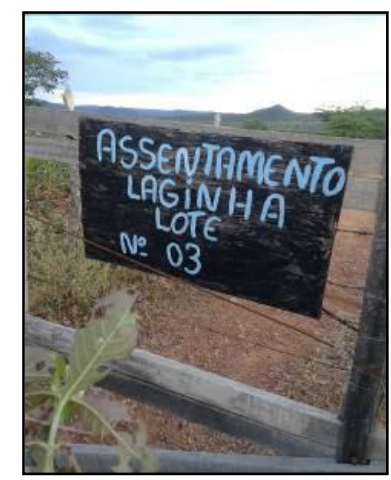

Figura 2 - Distância entre o assentamento e a sede do município (Serra Talhada). Fonte: Google Maps.

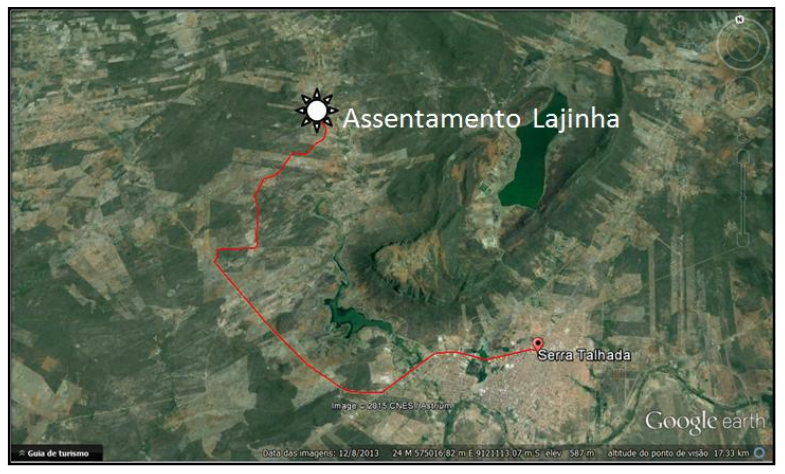




\section{Biodigestor}

O biodigestor é uma tecnologia alternativa que vem sendo utilizada há vários anos, porém, sua implantação na agricultura familiar vem crescendo aos poucos, como alternativa a fim de melhorar a qualidade de vida dessas pessoas, assim como uma forma de aproveitamento dos resíduos produzidos na propriedade para uma melhoria do meio ambiente e diminuição dos custos da família com a utilização de botijões de gás liquefeito de petróleo (GLP). Através do biodigestor as famílias aproveitam o esterco produzido nos currais, que o transformará em gás inflamável (Biogás), através da mistura de gases, formado pelo processo dos microorganismos sem a presença de oxigênio (fermentação anaeróbica), que passa pelos processos das frações gasosa, liquida e sólida. Onde as duas últimas geram subprodutos que podem ser utilizados como fertilizantes ou na criação de peixes (MATTOS, 2011).

Na região semiárida o gás oriundo do biodigestor é considerado um produto de grande importância devido apresentar um baixo custo, necessitando de materiais de fácil acesso pelos produtores rurais, como também a facilidade com que se realiza a sua manutenção. A utilização do biogás é satisfatória devido o mesmo não eliminar fumaça, mau cheiro na cozinha, ser higiênico e não deixar nenhum resíduo nas panelas (RUFINO \& QUEIROZ, 2011).

No Assentamento Laginha a iniciativa de se utilizar deste recurso para aproveitar os resíduos provenientes da propriedade, fez com que a família se sentisse mais valorizada por se tornar multiplicador do uso desta tecnologia na região, além de elevar os custos da família, já que não retiram dos seus recursos extras para utilização de gás liquefeito na propriedade, como também ainda se aproveitam do biodigestor para produção de hortaliças e plantas medicinais na copa do biodigestor no intuito de diminuir qualquer resquício de mau cheiro (Figura 3).

Figura 3 - Biodigestor com produção de hortaliças e plantas medicinais. Fonte: Própria.

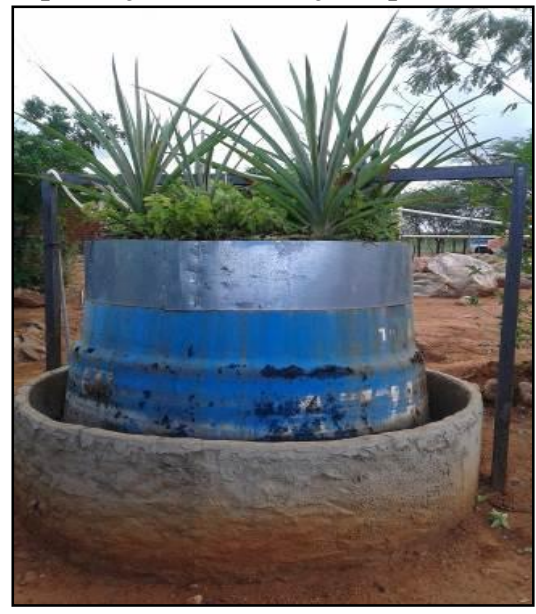




\section{Minhocário}

A minhocultura é uma atividade que proporciona a produção de composto orgânico de excelente qualidade, utilizado pela a agricultura familiar como insumo para adubação das culturas agrícolas.

O húmus de minhoca, além de ser rico em nutrientes para as plantas, ajuda a melhorar as características físico-quimicas do solo, como a aeração e a retenção de água. Por ser um material orgânico, sua utilização também auxilia no aumento da biodiversidade dos microrganismos do solo, tendo como consequência uma maior estabilidade do agroecossistema. (SCHIEDECK, G. et al., 2007, p.1).

Na propriedade visitada, foram encontrados dois minhocários, um em atividade de produção de húmus e o outro vazio, para ser utilizado após o processo de decomposição dos resíduos (fezes de caprinos, restos de cultura e podas de árvores) pelas minhocas.

Quando o húmus está pronto para utilização no sistema agroecológico da propriedade, ou seja, a horta, as frutíferas, a capineira e a produção de mudas; o outro minhocário é preenchido com novos resíduos e a transferência das minhocas ocorre através de uma abertura na parte inferior rente ao solo por um cano de PVC ligando um minhocário ao outro, conforme figura 4.

Figura 4 -Orifício para ligação entre os minhocários através do cano de PVC, para passagem das minhocas. Fonte: Própria.

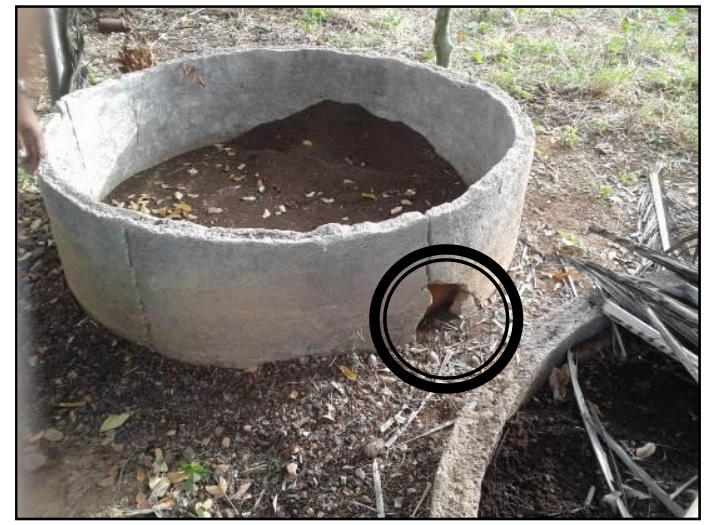

\section{Biofertilizante}

O biofertilizante é um produto natural obtido por meio dos processos aeróbicos ou anaeróbicos, fermentação de materiais orgânicos com água. Sua composição pode ser complexa e 
variável, pois depende do material utilizado, favorecendo os macros e micros elementos necessários à nutrição vegetal (SILVA et al., 2007).

Sobre forma líquida, o biofertilizante contém uma composição de nutrientes essenciais às plantas, principalmente nitrogênio e fósforo, atuando como fertilizante e também como defensivo agrícola, erradicando pragas, doenças e insetos (BARROS, 2015).

No assentamento, a família visitada utiliza biofertilizante a partir dos dejetos dos caprinos, suínos e galinhas, além dos restos das culturas e uma porção de leite. A utilização do leite foi justificada alegando que provoca uma maior ação das bactérias e torna mais rápida a fermentação do produto. O processo é realizado de forma aeróbica em manilha de concreto (Figura 5).

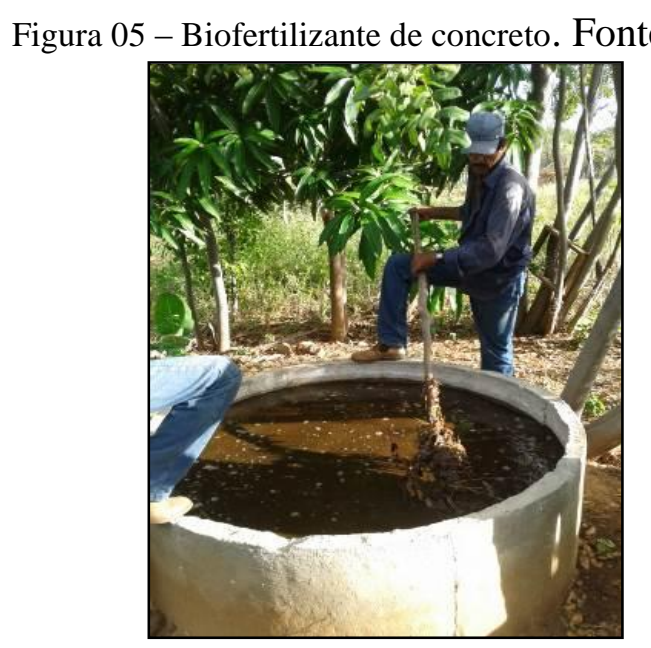

\section{Conclusões}

O biodigestor é de fundamental importância para um aproveitamento de resíduos pelas famílias de pequenas propriedades rurais, além de os tornarem exemplos de preocupação com uso dos resíduos gerados na propriedade como também com a gestão ambiental.

A compostagem orgânica e o biofertilizante, tem como importância na melhoria do solo para o desenvolvimento das culturas vegetais, disponibilizando a eles os nutrientes necessários para seu crescimento. Assim também o biofertilizante ajuda no controle de pragas, sendo utilizada como um defensivo natural.

Podemos considerar que as tecnologias citadas têm grande importância para melhoria da qualidade de vida dos agricultores familiares, como também na diminuição do custo com a produção, geração de renda extra e aproveitamento dos resíduos eliminados contribuindo com o meio ambiente. 


\section{Referências}

ALMEIDA, J. R. Gestão ambiental para o desenvolvimento sustentável. Rio de Janeiro: Thex: Almeida Cabral, 2012.

ASA. Articulação Semiárido Brasileiro. Caminhos para a convivência com o semi-árido. Recife: ASA, out 2010.

BARROS, T. D. Biofertilizante. Brasília, DF: EMBRAPA, 2015. Disponível em:< http://www.agencia.cnptia.embrapa.br/gestor/agroenergia/arvore/CONT000fjaakw3q02wyiv809gkz 5151b3dhe.html>. Acesso em: 30 jun. 2015.

BERTÉ, R. Agricultura familiar e os desafios da sustentabilidade econômica e ambiental. Publicado em 09 de julho de 2014. Disponível em < http://www.gazetadopovo.com.br/opiniao/artigos/agricultura-familiar-e-os-desafios-dasustentabilidade-economica-e-ambiental-eangj14y825ck6wk2tldvyi4u>. Acesso em: 01 jul. 2015.

BRASIL. Lei $\mathbf{n}^{\mathbf{0}} \mathbf{1 2 . 2 0 5}$, de 2 de agosto de 2011. Institui a Política Nacional de Resíduos Sólidos. Disponível em:< http://www.planalto.gov.br/ccivil_03/_ato2007-2010/2010/lei/112305.htm>. Acesso em: 15 jun. 2015.

COIMBRA, R. M. Sistema Nacional de Gerenciamento de Recursos Hídricos. Anais. In: Seminário Técnico sobre Sistema Nacional de Gerenciamento de Recursos Hídricos. São Paulo, maio/1992. São Paulo: FUNDAP, 1992, p. 10-16.

CRUZ NETO, O. O trabalho de campo como descoberta e criação. In: MINAYO, Maria Cecília de Souza (org.). Pesquisa Social: teoria, método e criatividade. 19. ed. Petrópolis: Vozes, 2001. (Coleção temas sociais).

DRUMOND, M. A. Técnicas e ferramentas participativas para a gestão de unidades de conservação. Realização Programa Área Protegidas da Amazônia - ARPA e Cooperação Técnica Alemã - GTZ. Brasília: MMA, 2009. (Cadernos ARPA, 4). Disponível em: < www.programaarpa.gov.br/wp.../caderno4ArpaTecnicasParticipativas.pdf.>. Acesso em: 5 jun. 2015.

EMBRAPA. Empresa Brasileira de Pesquisa Agropecuária. Tratamento de resíduos animais. Disponível em: < agrosustentavel.com.br/dow nloads/tratamento_de_residuos_animais.pdf>. Acesso em: 15 jun. 2015.

GLOAGEN, R. A. B. G. et al. Diagnóstico preliminar de impactos ambientais na micro-bacia do Ribeirão do Machado em Cruz das Almas - BA. Resumos do V Congresso Brasileiro de Agroecologia Guarapari, ES, 01 a 04 de outubro de 2007. Revista Brasileira de Agroecologia/out. 2007. Vol.2 No.2. Disponível em $<$ http://www.abaagroecologia.org.br/revistas/index.php/rbagroecologia/article/view/7350/5368>. Acesso em $22 / 06 / 2015$. 
MATTOS, L.C. Manual do biodigestor sertanejo. Recife: Projeto Dom Helder Câmara, 2011. In: RUFINO E QUEIROZ. Biodigestor. 2011.

PETERSEN, P. Agroecologia como estratégia para convivência com o semiárido. In: GALINDO, Wedna (Org.). Vozes da convivência com o semiárido. Recife: Centro Sabiá, 2013.

SCHIEDECK, G.; SCHWENGBER, J.E.; GONÇALVES, M. de M.; SCHIAVON, G. de A.; CARDOSO, J.H. Minhocário campeiro de baixo custo para a agricultura familiar. Pelotas: Embrapa Clima Temperado, 2007. (Comunicado Técnico, 171). Disponível em: <https://www.embrapa.br/busca-de-publicacoes/-/publicacao/746035/minhocario-campeiro-debaixo-custo-para-a-agricultura-familiar> Acesso em 25 jun. 2015.

SEIFFERT, M. E. B. Gestão ambiental: instrumentos, esferas de ação e educação ambiental. 3. Ed. São Paulo: Atlas, 2014.

SILVA, A. F. et al. Preparo e uso de biofertilizantes líquidos. Comunicado Técnico, 130 online. Petrolina, PE: EMBRAPA, maio 2007. Disponível em: <http://www.cpatsa.embrapa.br>. Acesso em: 10 jun. 2015.

YURI, F. Gestão ambiental na agropecuária. Disponível em: < eugestor.com/editoriais/2014/10/gestao-ambiental-na-agropecuaria/ Acesso em: 26 jun. 2015. 